\title{
AS PESQUISAS EM EDUCAÇÃO ESPECIAL NA ANPED: A PRODUÇÃO DO CONHECIMENTO NAS REUNIÕES CIENTÍFICAS NACIONAIS
}

\author{
LAS INVESTIGACIONES EN EDUCACIÓN ESPECIAL EN LA ANPED: LA \\ PRODUCCIÓN DEL CONOCIMIENTO EN LAS REUNIONES CIENTÍFICAS \\ NACIONALES
}

\author{
RESEARCH ON SPECIAL EDUCATION IN THE ANPED: PRODUCTION OF \\ KNOWLEDGE ON NATIONAL SCIENTIFIC MEETINGS
}

Mariana Luzia Corrêa THESING ${ }^{1}$

Fabiane Adela Tonetto COSTAS ${ }^{2}$

RESUMO: Este texto apresenta uma análise dos trabalhos publicados nas últimas seis Reuniões Científicas Anuais da ANPEd (2010, 2011, 2012, 2013, 2015 e 2017), especificamente no Grupo de Trabalho Educação Especial (GT 15). A análise dos dados mostrou, dentre outros elementos, que um significativo número de pesquisas está voltado às políticas públicas, à surdez, às práticas pedagógicas e ao Atendimento Educacional Especializado, interesses de pesquisa que podem estar relacionados à proposição da Política Nacional da Educação Especial de 2008.

PALAVRAS-CHAVE: Educação especial. ANPED. GT educação especial.

RESUMEN: Este texto presenta un análisis de los trabajos publicados en las últimas seis Reuniones Científicas anuales de la ANPEd (2010, 2011, 2012, 2013, 2015 y 2017), específicamente en el Grupo de Trabajo Educación Especial (GT 15). El análisis de los datos mostró, entre otros elementos, que un significativo número de investigaciones está orientado a las políticas públicas, a la sordera, a las prácticas pedagógicas ya la Atención Educativa Especializada, intereses de investigación que pueden estar relacionados a la proposición de la Política Nacional de Educación Especial 2008.

PALABRAS CLAVE: Educación especial. ANPED. GT educación especial.

\footnotetext{
${ }^{1}$ Universidade Federal de Santa Maria (UFSM), Santa Maria - RS - Brasil. Professora do Colégio de Aplicação da Universidade Federal de Santa Catarina (CA/UFSC). Doutoranda do Programa de Pós-Graduação em Educação. ORCID: http://orcid.org/0000-0001-5864-7091.E-mail: marluzcor@gmail.com

${ }^{2}$ Universidade Federal de Santa Maria (UFSM), Santa Maria - RS - Brasil. Professora do Programa de PósGraduação em Educação e do Departamento de Fundamentos da Educação, do Centro de Educação. Doutorado em Educação (UFRGS) e Pós-Doutorado pela Universidade do Minho - Portugal. ORCID: https://orcid.org/0000-0003-3698-2782. E-mail: fabicostas@gmail.com
} 
ABSTRACT: This paper presents an analysis of the researches published in the last six Annual Scientific Meetings of ANPEd (2010, 2011, 2012, 2013, 2015 and 2017), specifically in the Special Education Working Group (WG 15). Data analysis showed, among other elements, that a significant number of researches are focused on public policies, deafness, pedagogical practices and Specialized Educational Attendance, research interests that may be related to the National Special Education Policy proposition of 2008.

KEYWORDS: Special education. ANPED. GT special education.

\section{Introdução}

Desvelar o campo da pesquisa na área da Educação Especial, em âmbito nacional, faz perceber a potência de alguns temas, as lacunas de outros e conhecer as pesquisas realizadas no campo de estudos. A partir da proposição um novo cenário educacional, tendo em vista a Educação Especial assumida nas instituições de ensino na perspectiva da educação inclusiva, em que discussões recentes visam transformar as legislações referentes ao público-alvo, suas especificidades e redes de atendimento (Projeto de Lei, s/n, 2019), as pesquisas voltam-se a diferentes temas que são caros à proposição de instituições inclusivas.

A pesquisa no campo da Educação Especial tem apresentado um crescente número de investigações que discutem os processos inclusivos a partir de distintas perspectivas e análises. Essas investigações constituem-se como um espaço cada vez mais fortalecido pelos interesses dos pesquisadores nos processos inclusivos educacionais e pelas questões neles imbricadas. Há, entre as pesquisas realizadas, uma multiplicidade de objetos de estudos que abrangem: os processos formativos dos professores, as políticas públicas que orientam as ações nas realidades escolares e os processos inclusivos com seus desafios nas instituições educacionais da Educação Básica e Superior.

Com base nessas premissas, este texto apresenta resultados de uma pesquisa realizada em seis Reuniões Científicas Anuais da Associação Nacional de Pós-Graduação e Pesquisa em Educação - ANPEd realizadas nos anos de 2010, 2011, 2012, 2013, 2015 e 2017³, especificamente no Grupo de Trabalho Educação Especial - GT 15.

\footnotetext{
${ }^{3}$ A reunião realizada no ano de 2019 não foi incluída para análise, pois este texto foi enviado para este periódico em período anterior à realização desta última reunião nacional.
} 


\section{Método}

A metodologia de pesquisa centrou-se na pesquisa da pesquisa em educação (SÁNCHEZ GAMBOA, 2007) a partir da leitura flutuante dos resumos e seus atinentes textos, da modalidade trabalhos completos e pôsteres, publicados nos sites das Reuniões Científicas Anuais da ANPEd, especificamente no Grupo de Trabalho 15 - Educação Especial, nos últimos seis anos (2010, 2011, 2012, 2013, 2015 e 2017).

Após a leitura dos resumos/textos, foi elaborada uma tabela preliminar com vistas a orientar a coleta dos seguintes dados: número do trabalho, título do trabalho, autores do trabalho, instituição de ensino, palavras-chave, questões e objetivos de pesquisa, metodologia e resumo do trabalho. A partir da tabulação desses dados preliminares, tabularam-se novamente os resumos/textos com os seguintes indicadores: regiões originárias das pesquisas, instituições de ensino de origem e suas naturezas (público, privada, comunitária), objetos de estudo, abordagens metodológicas e técnicas/instrumentos utilizados.

A pesquisa, configurada como uma "pesquisa da pesquisa em educação", tem o objetivo de "refletir sobre a prática da pesquisa educativa" (SÁNCHEZ GAMBOA, 2007, p. 26). Segundo o autor, esse tipo de estudo busca averiguar "que tipo de pesquisa se realiza, que tipos de conteúdos se desenvolvem, sua qualidade, sua utilidade etc.” (p. 60). Para o autor,

Todo o pesquisador, por mais original e precoce que seja, precisa realizar uma leitura diferenciada (leitura epistemológica) de outras pesquisas. Sem dúvida, trata-se de uma maneira de se familiarizar com a produção científica, o que consegue com a leitura crítica de outras pesquisas, relatórios de investigação ou teses. (SÁNCHEZ GAMBOA, 2007, p. 60).

Na busca pelas pesquisas desenvolvidas no GT 15 - Educação Especial da ANPEd, considerado como um banco de dados das produções realizadas, a pesquisa configura-se também como um estado do conhecimento (MOROSINI, 2015), de abordagem qualiquantitativa (MARCONI; LAKATOS, 2009), que teve o objetivo de identificar elementos referentes às produções e às pesquisas do GT, como as instituições de ensino superior (IES) e regiões de origem, as abordagens teórico-metodológicas, seus instrumentos e os temas/objetos de análise mais investigados ${ }^{4}$.

O estado do conhecimento, para Morosini (2015), “constitui-se numa importante fonte para a produção, não só por acompanhar todo o processo monográfico, mas prioritariamente,

${ }^{4}$ Outras pesquisas, com o objetivo de analisar as produções científicas do GT 15 da ANPEd, com diferentes enfoques e recortes, também podem ser compreendidas como "pesquisa da pesquisa em educação" (SANCHEZGAMBOA, 2007), dentre as quais citamos Garcia; Michels (2011); Jesus; Barreto; Gonçalves (2011); e Ferreira; Bueno (2011). 
por contribuir para a ruptura com os pré-conceitos que o pesquisador porta ao iniciar o seu estudo" (MOROSINI, 2015, p. 102-103). Nessa discussão, Romanowski e Ens (2006) consideram que as pesquisas do tipo estado de conhecimento:

[...] procuram identificar os aportes significativos da construção da teoria e prática pedagógica, apontar as restrições sobre o campo em que se move a pesquisa, as suas lacunas de disseminação, identificar experiências inovadoras investigadas que apontem alternativas de solução para os problemas da prática e reconhecer as contribuições da pesquisa na constituição de propostas na área focalizada. (ROMANOWSKI; ENS, 2006, p. 39).

$\mathrm{O}$ recorte temporal justifica-se pelo interesse em conhecer as investigações mais recentes no campo, tendo em vista as pesquisas já realizadas sobre/no campo (MARQUES et al., 2008; FERREIRA; BUENO, 2011). A escolha pelas Reuniões Científicas Anuais da ANPEd, como o banco de dados para essa pesquisa, justifica-se pela sua excelência, por ser considerada associação qualificada na área de pós-graduação em educação do país que socializa/divulga as pesquisas científicas sobre as diversas áreas da educação e seus temas da atualidade e por disponibilizar online suas produções acadêmicas.

\section{Discussão e resultados}

\section{Produções no GT 15 e as regiões do país}

A pesquisa em Educação Especial tem apresentado um crescente número de investigações voltadas aos processos inclusivos nas instituições de ensino regular, suas formas de gestar, suas bases legais e epistemológicas. O levantamento das pesquisas apresentadas no GT 15 - Educação Especial reuniu 145 trabalhos, na modalidade trabalhos completos e pôsteres, no decorrer das seis Reuniões já citadas. Desses, 126 publicações são referentes a trabalhos completos e 19 são pôsteres.

Do número total de publicações, 53 são provenientes da região sul do país (37\%); 48 da região sudeste (33\%); 23 da região nordeste (16\%); 16 da região centro-oeste $(11 \%)$ e cinco da região norte do país (3\%). A figura 1 ilustra a correspondência do número de trabalhos e suas regiões originárias. 
Figura 1 - Gráfico do número de trabalhos por regiões originárias - GT 15 Educação Especial ANPEd (últimas seis Reuniões Científicas Anuais).

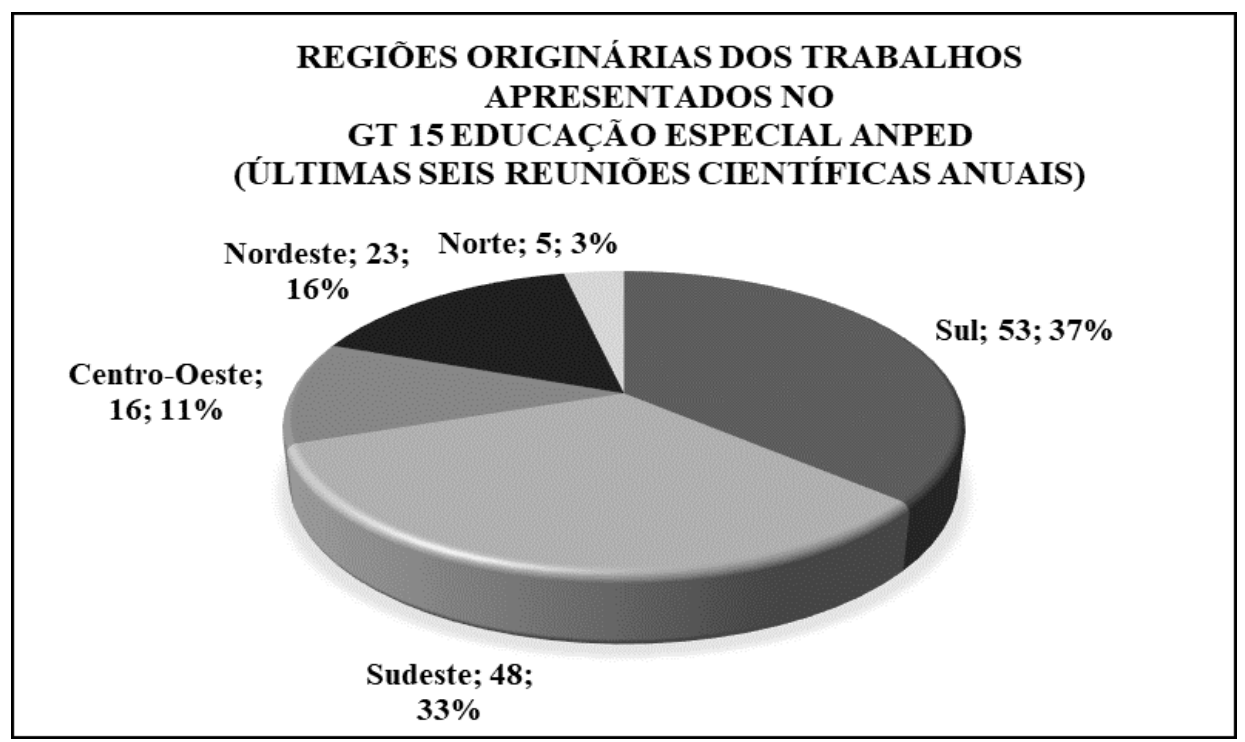

Fonte: elaborada pelas autoras.

De forma geral, a Região Sul destaca-se no decorrer das seis Reuniões Científicas Anuais da ANPEd por apresentar um número maior de produções, seguida das Regiões Sudeste e Nordeste do país. A figura 2 apresenta detalhadamente o número dos trabalhos conforme a região do país e o ano da Reunião. Destaca-se que a última reunião científica ( $38^{\mathrm{a}}$, realizada em São Luís/MA, 2017) foi a que apresentou o menor número de trabalhos aprovados, totalizando apenas 18 trabalhos entre trabalhos completos (16) e pôsteres (2) Para maior detalhamento dessa constatação, o Gráfico 2 apresenta o recorte temporal elegido para a análise.

${ }^{5} \mathrm{Na} 37^{\mathrm{a}}$ Reunião Científica (2015), foram aprovados 31 trabalhos, dentre as modalidades Trabalho Completo e Pôsteres, foram aprovados. Na $36^{\mathrm{a}}$ (realizada em 2013), o total de trabalhos foi de 22 produções; na $35^{\mathrm{a}}$ Reunião

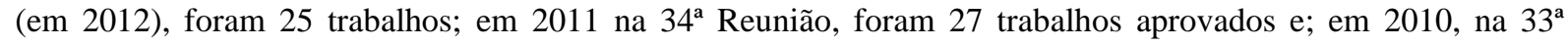
Reunião apenas 22 trabalhos aprovados. 
Figura 2 - Gráfico do número dos trabalhos apresentados conforme as regiões do país - GT 15 Educação Especial - ANPEd (últimas seis Reuniões Científicas Anuais).

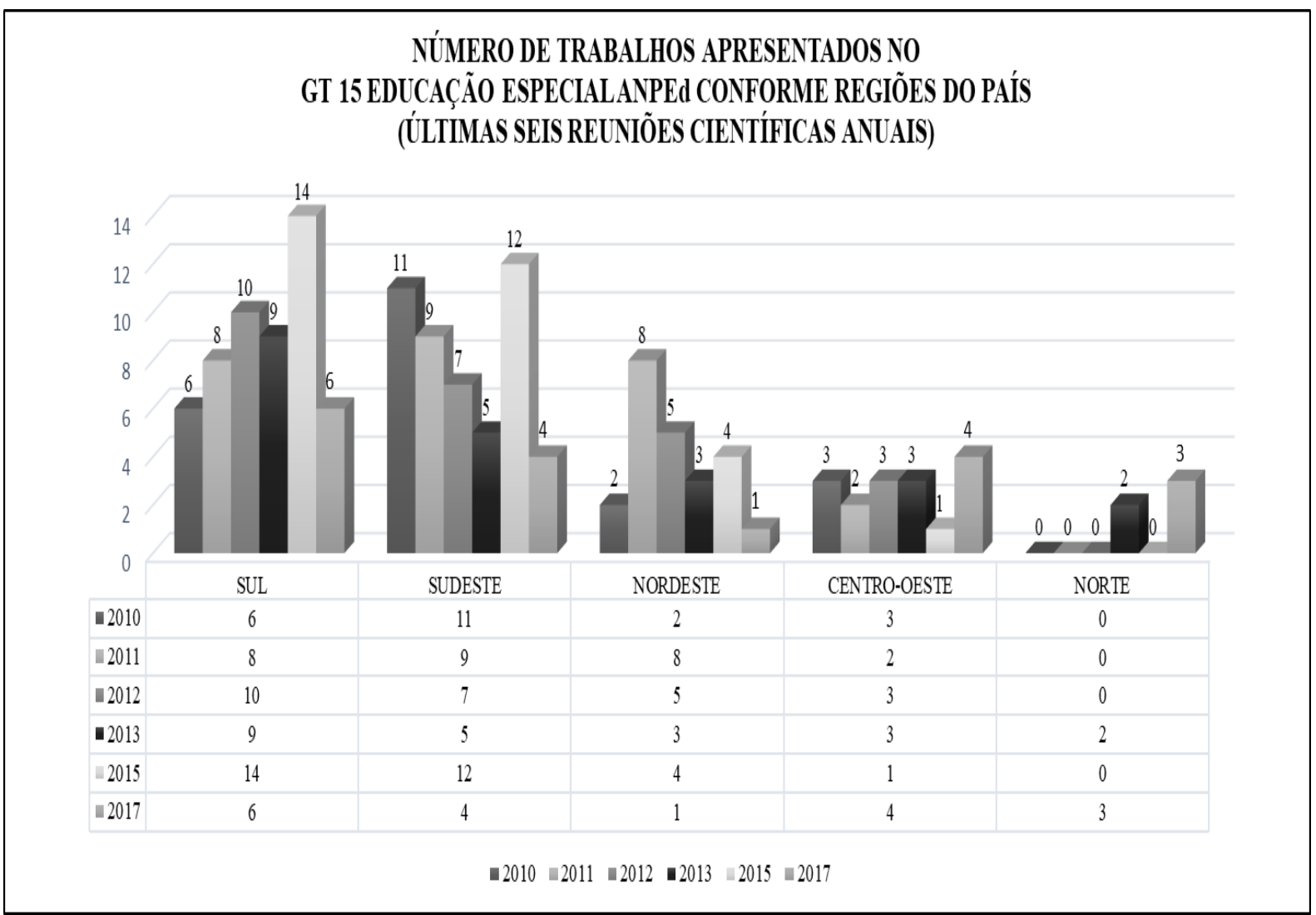

Fonte: elaborada pelas autoras.

Tendo em vista a baixa participação da região Norte nas últimas seis reuniões científicas anuais, buscamos identificar os programas de pós-graduação em educação em atividade situados na Região Norte e quais deles continham linhas de pesquisa voltadas à área da Educação Especial. Conforme a Plataforma Sucupira há o total de 177 programas de pósgraduação em educação no país ${ }^{1}$, sendo que há apenas 13 em atividade na Região Norte. Desses 13, onze são programas de pós-graduação acadêmicos e dois programas são voltados à educação profissional. Dos programas de pós-graduação em educação acadêmicos, apenas um programa contém uma linha de pesquisa voltada à pesquisa em Educação Especial: o Programa de Pós-Graduação em Educação da Universidade Federal do Amazonas, com cursos de Mestrado e Doutorado, conforme indica a Tabela $1^{6}$.

${ }^{6}$ Conforme a Plataforma Sucupira, há 177 Programas de Pós-Graduação em Educação no país, sendo que 56 ofertam apenas cursos de mestrado acadêmicos em educação, 47 cursos de mestrado profissionais em educação e 74 cursos ofertam cursos de mestrado e doutorado acadêmicos em educação, totalizando 251 cursos. 
Tabela 1 - Programas de Pós-Graduação em Educação acadêmicos e profissionais da Região Norte do país e suas linhas de Pesquisa.

Programas de Pós-Graduação em Educação Acadêmicos e Profissionais e Linhas de Pesquisa - Região Norte

\begin{tabular}{|c|c|}
\hline Universidade Federal Do Acre (ME) & $\begin{array}{l}\text { Programa de Pós-Graduação em Educação } \\
\text { Curso de Mestrado Acadêmico em Educação } \\
\text { Linhas de Pesquisa: } \\
\text { - Políticas e Gestão Educacional } \\
\text { - Formação de Professores e Trabalho Docente }\end{array}$ \\
\hline $\begin{array}{l}\text { Universidade Federal Do Amapá } \\
\text { (ME) }\end{array}$ & $\begin{array}{l}\text { Programa de Pós-Graduação em Educação } \\
\text { Curso de Mestrado Acadêmico em Educação } \\
\text { Linhas de Pesquisa: } \\
\text { - Políticas Educacionais } \\
\text { - Educação, Culturas e Diversidade }\end{array}$ \\
\hline $\begin{array}{l}\text { Universidade Federal Do Amazonas } \\
\text { (ME/DO) }\end{array}$ & $\begin{array}{l}\text { Programa de Pós-Graduação em Educação } \\
\text { Cursos de Mestrado e Doutorado Acadêmicos em } \\
\text { Educação } \\
\text { Linhas de Pesquisa: } \\
\text { - Processos Educativos e Identidades Amazônicas } \\
\text { - Educação, Políticas Públicas e Desenvolvimento Regional } \\
\text { - Formação e Práxis do Educador frente aos Desafios } \\
\text { Amazônicos } \\
\text { - Educação Especial e Inclusão no Contexto Amazônico. }\end{array}$ \\
\hline $\begin{array}{l}\text { Universidade Do Estado Do Pará } \\
\text { (ME) }\end{array}$ & $\begin{array}{l}\text { Programa de Pós-Graduação em Educação } \\
\text { Curso de Mestrado Acadêmico em Educação } \\
\text { Linhas de Pesquisa: } \\
\text { - Formação de Professores e Práticas Pedagógicas } \\
\text { - Saberes Culturais e Educação na Amazônia }\end{array}$ \\
\hline $\begin{array}{l}\text { Universidade Federal Do Oeste Do } \\
\text { Pará (ME) }\end{array}$ & $\begin{array}{l}\text { Programa de Pós-Graduação em Educação } \\
\text { Curso de Mestrado Acadêmico em Educação } \\
\text { Linhas de Pesquisa: } \\
\text { - História, Políticas e Gestão na Educação na Amazônia } \\
\text { - Práticas Educacionais, Linguagens e Tecnologias }\end{array}$ \\
\hline \multirow[t]{3}{*}{ á } & $\begin{array}{l}\text { Programa de Pós-Graduação em Educação } \\
\text { Curso de Mestrado e Doutorado Acadêmico em } \\
\text { Educação } \\
\text { Linhas de Pesquisa: } \\
\text { - Políticas Públicas Educacionais } \\
\text { - Educação, Cultura e Sociedade } \\
\text { - Formação de Professores, Trabalho Docente, - Teorias e } \\
\text { Práticas Educativas }\end{array}$ \\
\hline & $\begin{array}{l}\text { Programa de Pós-Graduação em Educação e Cultura } \\
\text { Curso de Mestrado Acadêmico em Educação e Cultura } \\
\text { Linhas de Pesquisa: } \\
\text { - Educação Básica, Tecnologias, Trabalho e Movimentos } \\
\text { Sociais na Amazônia } \\
\text { - Educação, Cultura e Linguagem }\end{array}$ \\
\hline & $\begin{array}{l}\text { Programa de Pós-Graduação em Currículo e Gestão da } \\
\text { Escola Básica } \\
\text { Curso de Mestrado Acadêmico em Currículo e Gestão } \\
\text { da Escola Básica } \\
\text { Linhas de Pesquisa: } \\
\text { - Currículo da Educação Básica } \\
\text { - Gestão e Organização do Trabalho Pedagógico na Escola } \\
\text { Básica }\end{array}$ \\
\hline
\end{tabular}




\begin{tabular}{|c|c|}
\hline $\begin{array}{l}\text { Universidade Estadual De Roraima } \\
\text { (ME) }\end{array}$ & $\begin{array}{l}\text { Programa de Pós-Graduação em Educação } \\
\text { Curso de Mestrado Acadêmico em Educação } \\
\text { Linhas de Pesquisa: } \\
\text { - Formação, Trabalho Docente e Currículo } \\
\text { - Educação do Campo, Educação Indígena } \\
\text { Interculturalidade }\end{array}$ \\
\hline $\begin{array}{l}\text { Universidade Federal De Rondônia } \\
\text { (ME) }\end{array}$ & $\begin{array}{l}\text { Programa de Pós-Graduação em Educação } \\
\text { Curso de Mestrado Acadêmico em Educação } \\
\text { Linhas de Pesquisa: } \\
\text { - Formação Docente } \\
\text { - Políticas e Gestão Educacional }\end{array}$ \\
\hline & $\begin{array}{l}\text { Programa de Pós-Graduação em Educação Escolar } \\
\text { Curso de Mestrado Profissional em Educação Escolar } \\
\text { Linhas de Pesquisa: } \\
\text { - Práticas Pedagógicas, Inovações Curriculares e } \\
\text { Tecnológicas }\end{array}$ \\
\hline \multirow[t]{2}{*}{ Federal Do Tocantins } & $\begin{array}{l}\text { Programa de Pós-Graduação em Educação } \\
\text { Curso de Mestrado Acadêmico em Educação } \\
\text { Linhas de Pesquisa: } \\
\text { - Currículo, Formação de Professores e Saberes Docentes } \\
\text { - Estado, Sociedade e Práticas Educacionais }\end{array}$ \\
\hline & $\begin{array}{l}\text { Programa de Pós-Graduação em Educação } \\
\text { Curso de Mestrado Profissional em Educação } \\
\text { Linhas de Pesquisa: } \\
\text { - Currículos Específicos de Etapas e Modalidades de Educação } \\
\text { - Métodos e Técnicas de Ensinar e Aprender na Educação Básica }\end{array}$ \\
\hline
\end{tabular}

Fonte: Plataforma Sucupira - Cursos Recomendados e Reconhecidos - Área de Avaliação - Área de Conhecimento - Instituições de Ensino.

O número de programas de pós-graduação em educação da Região Norte e suas Linhas de Pesquisa voltadas às temáticas da área da Educação Especial pode ser um dos indicativos para compreender a baixa participação da região nos últimos eventos nacionais da ANPEd. Entretanto, entende-se que outras Linhas de Pesquisa, dentre elas as voltadas aos estudos sobre Formação de Professores, sobre Práticas Pedagógicas e sobre Políticas Públicas dos programas de pós-graduação acadêmicos e profissionais da região, certamente devam produzir pesquisas voltadas aos temas pertinentes da Educação Especial.

\section{As instituições originárias e suas naturezas}

Tendo em vista os 145 trabalhos tabulados nas últimas seis Reuniões Científicas Anuais da ANPEd, 123 trabalhos eram provenientes de instituições públicas do país (85\%), sendo a maioria deles advinda da Região Sul do país. Do número total, 16 trabalhos eram provenientes de instituições de natureza privada (11\%) - a maioria deles advinda da Região Sudeste do país -, cinco provenientes de instituições de ensino superior de natureza 
comunitária (3\%) e um trabalho com dois autores cujas instituições de ensino superior tinham naturezas distintas: o primeiro autor oriundo de uma IES de natureza pública e o segundo advindo de uma IES de natureza privada (1\%). A figura 3 sistematiza as produções conforme a natureza das instituições a que estão relacionadas.

Figura 3 - Gráfico: natureza das Instituições de Ensino Superior (IES) originárias das produções do GT 15, nos últimos seis anos.

\section{Natureza das Instituições de Ensino Superior (IES) das produções do} GT 15

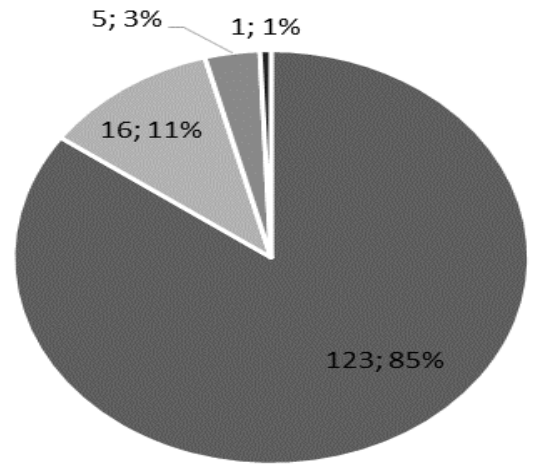

- Produções advindas de IES públicas

- Produções advindas de IES privadas

- Produções advindas de IES comunitária

- Produção advinda de IES pública/privada

Fonte: elaborada pelas autoras.

A Tabela $2^{7}$ apresenta o número de trabalhos apresentados em cada Reunião Científica Anual (33 a $\left.38^{\mathrm{a}}\right)$, separados por região, distribuídos de acordo com a natureza das instituições originárias dos trabalhos.

${ }^{7}$ As abreviações "PUB”, "PRI”, “COM”, "PUB/PRI” referem-se à natureza das instituições de ensino superior (IES): pública, privada, comunitária e público-privada, respectivamente. A abreviação PUB/PRI refere-se à situação em que a produção continha mais de um autor, filiados a diferentes instituições. Destaca-se que não foram encontrados em todas as reuniões científicas anuais trabalhos advindos de instituições de origem com naturezas "comunitária" e com autores de diferentes instituições para serem classificados como "públicoprivadas". Salienta-se que na $34^{\text {a }}$ Reunião Científica Anual da ANPEd só foram catalogados trabalhos advindos ou de instituições públicas ou de instituições privadas. 
Tabela 2 - Levantamento da Natureza das Instituições/Origem dos Trabalhos apresentados no GT 15 Educação Especial, na ANPEd nas últimas seis Reuniões Científicas Anuais da

ANPEd (2010, 2011, 2012, 2013, 2015 e 2017).

\begin{tabular}{|c|c|c|c|c|c|c|c|c|c|c|c|c|c|c|c|c|c|c|c|c|c|}
\hline & \multicolumn{4}{|c|}{$\begin{array}{c}33^{\mathrm{a}} \\
\text { ANPEd } \\
2010\end{array}$} & \multicolumn{2}{|c|}{$\begin{array}{c}34^{\mathrm{a}} \\
\text { ANPEd } \\
2011\end{array}$} & \multicolumn{2}{|c|}{$\begin{array}{c}35^{\mathrm{a}} \\
\text { ANPEd } \\
2012\end{array}$} & \multicolumn{3}{|c|}{$\begin{array}{c}36^{\mathrm{a}} \\
\text { ANPEd } \\
2013\end{array}$} & \multicolumn{3}{|c|}{$\begin{array}{c}37^{\mathrm{a}} \\
\text { ANPEd } \\
2015\end{array}$} & \multicolumn{2}{|c|}{$\begin{array}{c}38^{\mathrm{a}} \\
\text { ANPEd } \\
2017\end{array}$} & \multicolumn{5}{|c|}{$\begin{array}{c}\text { TOTAL } \\
\text { (Últimas seis Reuniões } \\
\text { Científicas Anuais) }\end{array}$} \\
\hline $\begin{array}{l}\text { Naturez } \\
\text { a IES/ } \\
\text { Região } \\
\text { do país }\end{array}$ & $\begin{array}{l}\mathrm{P} \\
\dot{U} \\
\mathrm{~B}\end{array}$ & $\begin{array}{l}P \\
R \\
I\end{array}$ & $\begin{array}{c}\mathrm{C} \\
\mathrm{O} \\
\mathrm{M}\end{array}$ & $\begin{array}{c}\text { PUB } \\
/ \\
\text { PRI }\end{array}$ & $\begin{array}{l}\text { P } \\
\text { Ú } \\
\text { B }\end{array}$ & $\begin{array}{l}\mathrm{P} \\
\mathrm{R} \\
\mathrm{I}\end{array}$ & $\begin{array}{l}P \\
\dot{U} \\
B\end{array}$ & $\begin{array}{c}\mathrm{P} \\
\mathrm{R} \\
\mathrm{I}\end{array}$ & $\begin{array}{l}P \\
\text { Ú } \\
\text { B }\end{array}$ & $\begin{array}{l}\mathrm{F} \\
\mathrm{P} \\
\mathrm{l}\end{array}$ & $\begin{array}{l}\mathrm{C} \\
0 \\
\mathrm{M}\end{array}$ & $\begin{array}{l}P \\
\text { Ú } \\
\text { B }\end{array}$ & $\begin{array}{l}P \\
R \\
I\end{array}$ & & $\begin{array}{l}\text { P } \\
\dot{U} \\
\text { B }\end{array}$ & $\begin{array}{l}\mathrm{P} \\
\mathrm{R} \\
\mathrm{I}\end{array}$ & $\begin{array}{l}\text { P } \\
\text { Ú } \\
\text { B }\end{array}$ & $\begin{array}{c}\mathrm{P} \\
\mathrm{R} \\
\mathrm{I}\end{array}$ & $\begin{array}{l}\mathrm{C} \\
\mathrm{O} \\
\mathrm{M}\end{array}$ & $\begin{array}{c}\text { PUB/ } \\
\text { PRI }\end{array}$ & TOTAL \\
\hline $\begin{array}{c}\text { Centro- } \\
\text { oeste }\end{array}$ & 3 & 0 & 0 & 0 & 1 & 1 & 3 & 0 & 3 & 0 & 0 & 0 & 1 & & 4 & 0 & 14 & 2 & 0 & 0 & 16 \\
\hline Nordeste & 2 & 0 & 0 & 0 & 8 & 0 & 4 & 1 & 3 & 0 & 0 & 4 & c & & 1 & 0 & 22 & 1 & 0 & 0 & 23 \\
\hline Norte & 0 & 0 & 0 & 0 & 0 & 0 & 0 & 0 & 2 & c & 0 & 0 & c & & 3 & 0 & 5 & 0 & 0 & 0 & 5 \\
\hline Sudeste & 8 & 3 & 0 & 0 & 9 & 0 & 7 & 0 & 5 & c & 0 & 8 & 4 & & 4 & 0 & 41 & 7 & 0 & 0 & 48 \\
\hline Sul & 3 & 1 & 1 & 1 & 7 & 1 & 8 & 2 & 7 & 1 & 1 & 12 & 1 & & 4 & 0 & 41 & 6 & 5 & 1 & 53 \\
\hline TOTAL & 16 & 4 & 1 & 1 & 25 & 2 & 22 & 3 & 20 & 1 & 1 & 24 & 6 & & 16 & 0 & 123 & 16 & 5 & 1 & 145 \\
\hline
\end{tabular}

Fonte: elaborada pelas autoras.

\section{Os temas/objetos de estudo das produções}

O levantamento dos objetos de estudo foi realizado a partir da leitura dos resumos e das palavras-chave dos trabalhos que, tabulados numa tabela, foram quantificados de acordo com o número de trabalhos cujo objeto de estudo estavam relacionados aos temas. Assim, com base na leitura dos textos e das palavras-chave, esses foram tabulados conforme os temas e objetos de estudo a que estavam relacionados. Dentre estes, citamos: "autismo"; "atendimento educacional especializado"; "adaptações curriculares"; "altas habilidades/superdotação"; "avaliação", "autoadvocacia/empoderamento"; "acesso e permanência no ensino superior"; "cegueira"; "discursos pedagógicos sobre inclusão"; "deficiência"; "formação docente"; “identidade"; "LIBRAS"; "práticas pedagógicas"; "políticas públicas"; "pareceres e diagnósticos"; "surdez"; "trabalho docente articulado", dentre outros.

O objetivo de conhecer as pesquisas desenvolvidas nos últimos anos está relacionado ao interesse de elencar os temas que estão sendo investigados no campo da Educação Especial 
e também de vislumbrar necessários objetos de estudo, num movimento de consolidação do campo científico e de construção do conhecimento na área. Para Morosini (2015), o levantamento das produções mais recentes na área é fundamental para o pesquisador interessado em justificar suas escolhas de pesquisa, pois the fornece conhecimentos acerca dos interesses de pesquisa mais desenvolvidos, como também sobre possíveis lacunas a serem pesquisadas sobre o tema em estudo. Esse movimento, conforme Morosini e Fernandes (2014), auxilia na elaboração de futuras pesquisas no campo científico, ao afirmarem que:

[...] no que diz respeito à fase exploratória, sua contribuição é ímpar porque nos dá uma visão do que já foi/está sendo produzido em relação ao objeto de estudo que selecionamos como tema de pesquisa; disso decorre que é possível construir uma avaliação do grau de relevância e da pertinência do tema inicialmente selecionado situando-o em um campo de produção de conhecimento. (MOROSINI; FERNANDES, 2014, p. 161, grifo nosso).

Constata-se uma variedade significativa de temas de estudos e de investigações entre as pesquisas na área (FELICIO; PEREZ CAMPOS, 2017). No entanto, muitos temas igualmente importantes para o campo, como por exemplo questões que interfaceiam gênero e deficiência $^{8}$, ainda não aparecem veiculados pelo GT, o que inclui, numa rápida pesquisa, os trabalhos apresentados na reunião de 2019. Os temas de estudo mais pesquisados dentre as produções apresentadas nas seis Reuniões Científicas alvo desta análise referem-se às políticas públicas relacionadas à Educação Especial, às práticas pedagógicas diante dos processos inclusivos, à surdez em diferentes contextos, ao Atendimento Educacional Especializado e à formação inicial/continuada dos professores de Educação Especial. Destacase que em alguns trabalhos há o estudo sobre mais de um tema de pesquisa. A Figura 4 apresenta os objetos de estudo com maior número de trabalhos a eles relacionados.

${ }^{8}$ Ver TORRES, N. E.; COSTAS, F. A. T. A articulação entre as categorias de gênero, deficiência e educação superior na produção científica brasileira. Revista Ibero Americana de Humanidades, Ciências e Educação, Criciúma, v. 6.n. 1, p. 111-121, 2020. ISSN-2446- 547X. 
Figura 4 - Gráfico: temas de pesquisa mais pesquisados nos últimos seis anos, no GT 15 Educação Especial, na ANPEd.

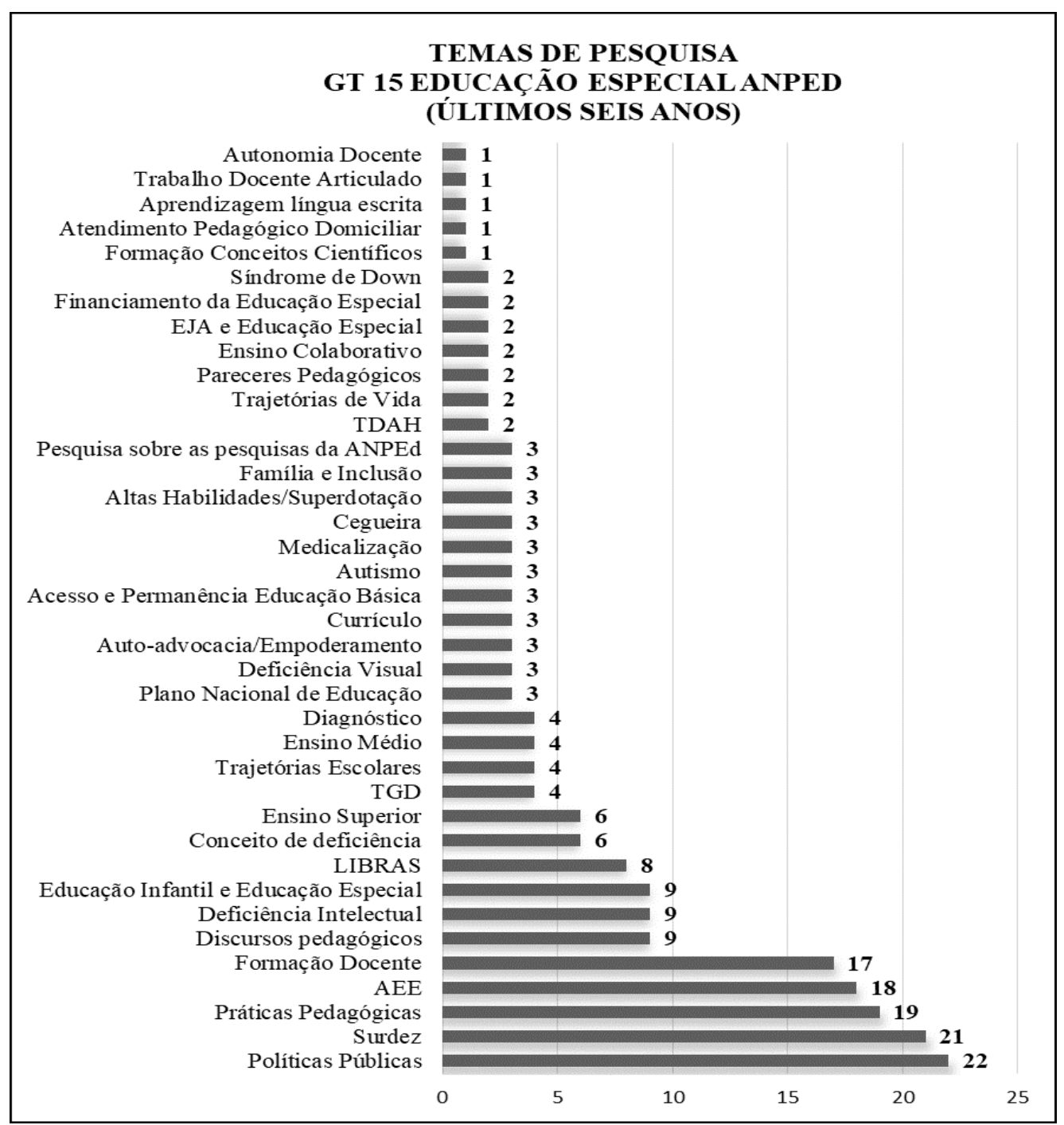

Fonte: elaborada pelas autoras.

\section{Abordagens metodológicas: tipos de pesquisa, técnicas e instrumentos metodológicos}

As pesquisas apresentaram diferentes metodologias de pesquisa. $\mathrm{O}$ estudo sobre metodologias de pesquisa não está associado apenas às formas de realizar as pesquisas, mas também a perspectivas de análise que podem, a partir da construção do conhecimento, contribuir para fazer a manutenção da condição social em que vivemos ou transformá-la. Definidas pelos autores, elas configuravam-se, em sua maior parte, como pesquisas de caráter qualitativo, classificadas como: pesquisa demográfica; bibliográfica; documental; etnográfica documental; exploratória; pesquisa-ação; pesquisa-ação colaborativo-crítica; histórica; pesquisa-intervenção; pesquisa biográfica. 
$\mathrm{Na}$ definição acerca da abordagem metodológica utilizada na pesquisa, alguns autores não explicitaram nos resumos/textos as suas perspectivas de pesquisa. Outros, entretanto, definiam-nas de forma dupla, afirmando a natureza da abordagem metodológica do estudo e a metodologia de pesquisa desenvolvida. Para a tabulação desses dados, foi realizada a leitura dos textos e respeitada a definição dos autores acerca das abordagens metodológicas utilizadas. A Figura 5 apresenta as metodologias de pesquisa definidas explicitamente pelos autores nos textos dos resumos/trabalhos completos relacionados.

Figura 5 - Gráfico: abordagens metodológicas/tipologias de pesquisa dos trabalhos, a partir da definição dos autores, publicados nas Reuniões Científicas Anuais da ANPEd (últimos seis anos)

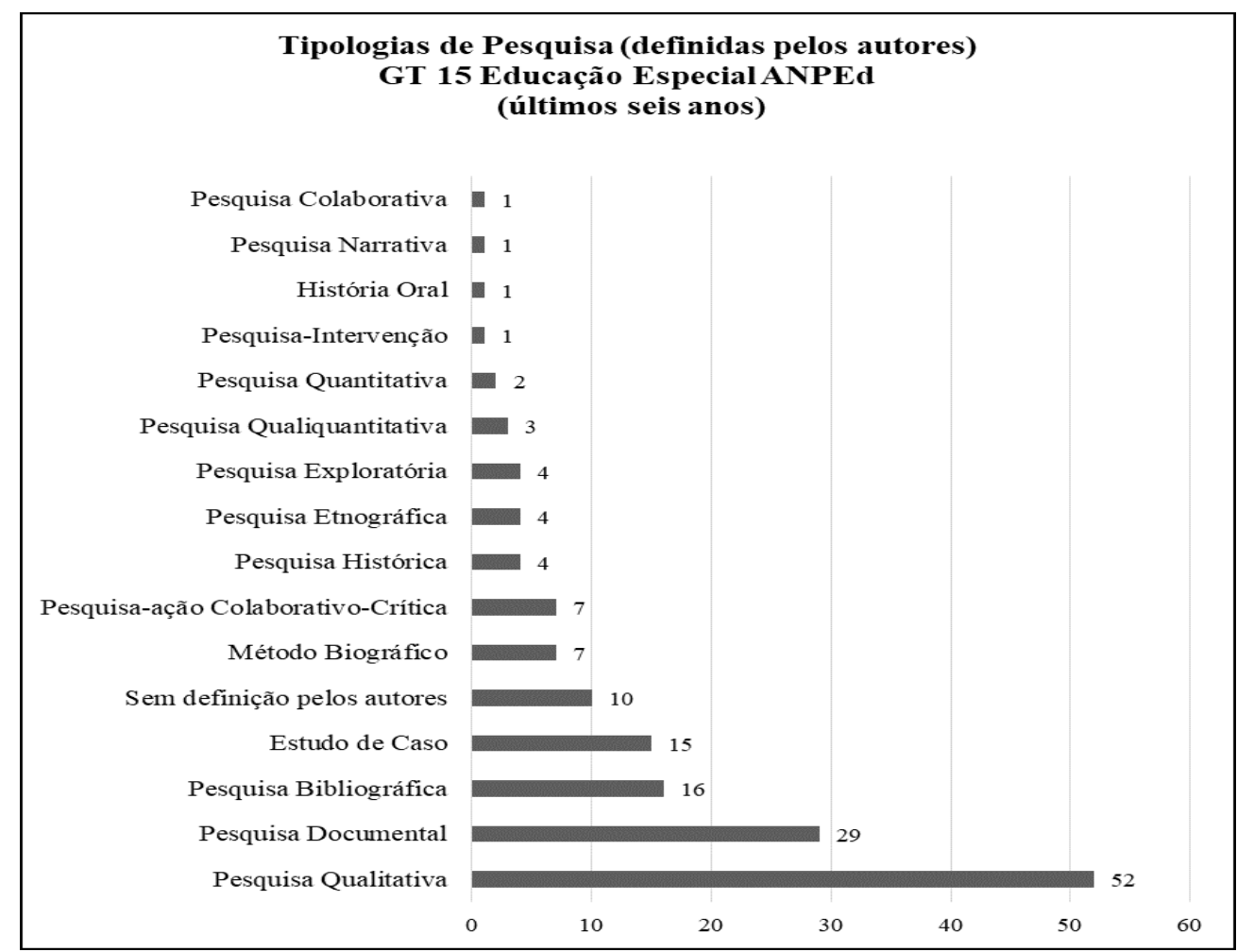

Fonte: elaborada pelas autoras.

Conforme o Gráfico 5, percebe-se uma predominância da pesquisa documental nos trabalhos publicados, seguido das escolhas metodológicas pelo estudo de caso e pela pesquisa bibliográfica. Do total de trabalhos, apenas um se define como pesquisa com a abordagem metodológica quantitativa, um pela abordagem de pesquisa qualiquantitativa e 40 (quarenta) definiram-se pela abordagem metodológica qualitativa (36\%).

Dentre as técnicas/instrumentos de pesquisa utilizados, os trabalhos citavam: entrevistas, observações, questionários; análise de documentos; revisão bibliográfica; videogravação; audiogravação; diário de campo; grupo focal; clínica biográfica; cartografia; 
estado de conhecimento. Destaca-se que a maior parte das pesquisas sinalizavam utilizar mais de uma técnica/instrumento de pesquisa em suas investigações. A figura 6 apresenta as técnicas/instrumentos utilizados nas pesquisas, explicitados pelos próprios autores nos textos relacionados.

Figura 6 - Gráfico: técnicas e instrumentos (conforme Marconi e Lakatos, 2009) utilizados com maior expressão nas pesquisas/trabalhos apresentados na ANPEd, GT 15 Educação Especial, nos últimos seis anos

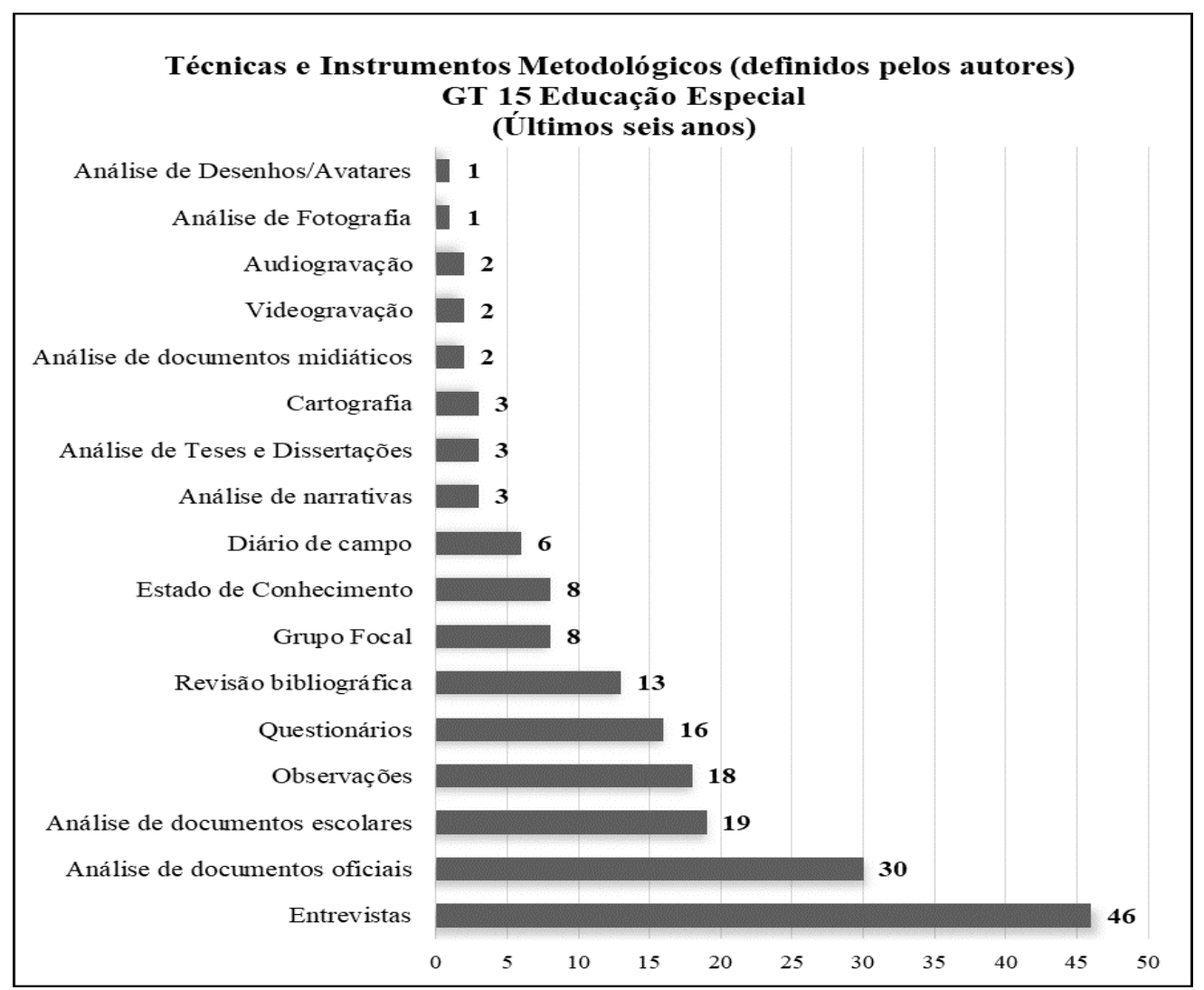

Fonte: elaborada pelas autoras.

\section{As pesquisas e suas abordagens teóricas}

As abordagens teóricas das produções foram elencadas a partir da leitura dos textos e da consulta às referências utilizadas. Assim como a tabulação das abordagens metodológicas de pesquisa, a classificação das abordagens teóricas que fundamentaram as produções foi realizada a partir da definição explícita, no corpo do texto, dos autores dos trabalhos. 
Figura 7 - Gráfico: abordagens teóricas, a partir da definição dos autores, dos trabalhos publicados nas Reuniões Científicas Anuais da ANPEd (nos últimos seis anos)

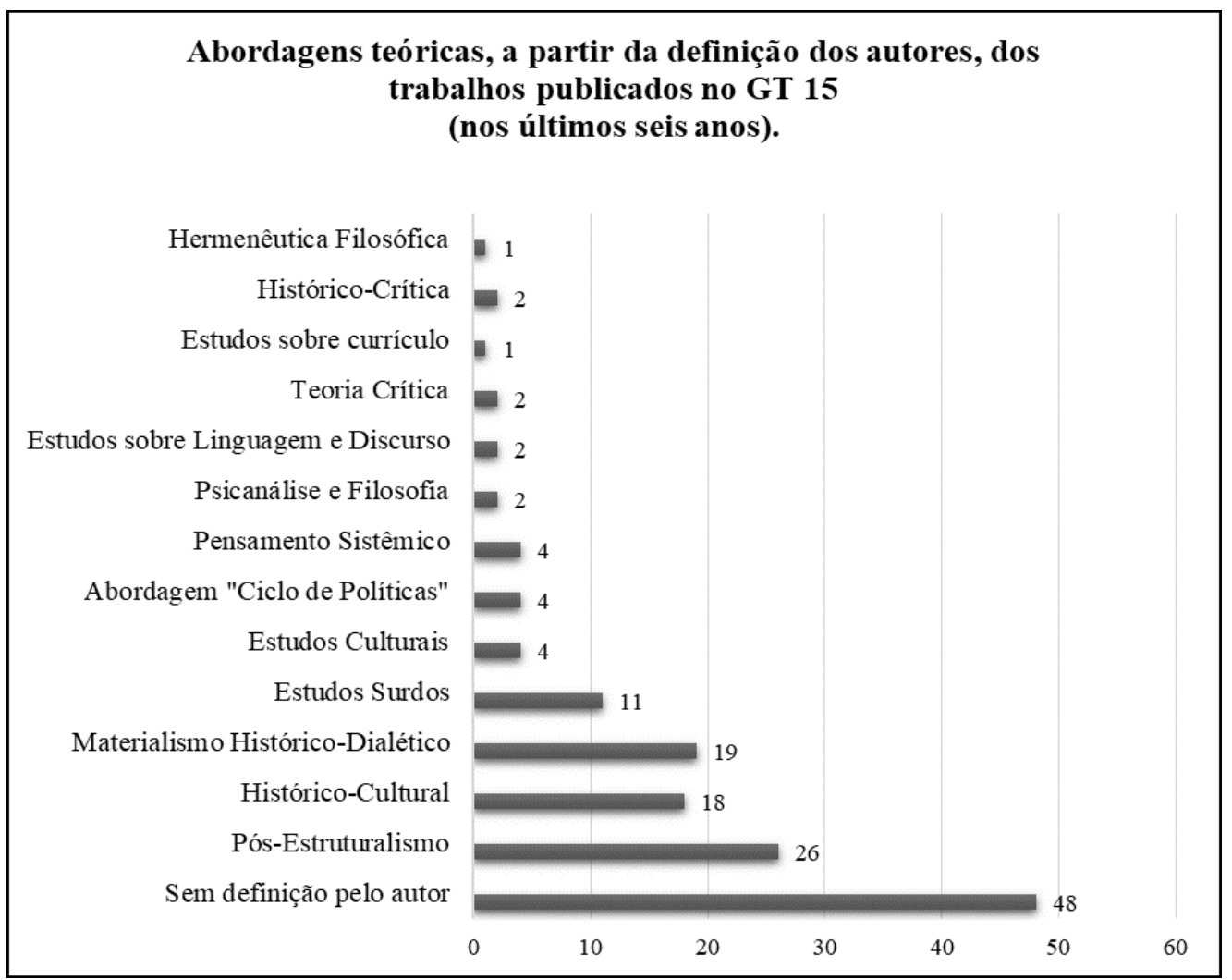

Fonte: elaborada pelas autoras.

A figura 7 revela as perspectivas teóricas mais utilizadas nos trabalhos publicados no GT 15, nos últimas Reuniões Anuais da ANPEd. Os estudos pós-estruturalistas embasam os estudos de um número (26) considerável de produções, sendo referendada em seis produções publicadas na última Reunião Científica Anual (38 Reunião Científica Anual, ocorrida em 2017). Esse número expressivo de pesquisas fundamentadas pelas perspectivas pósestruturalistas pode estar associado à chamada "virada linguística", que anunciou, a partir dos anos noventa, os preceitos das teorias pós-críticas e as rupturas propostas nas formas de entender os diferentes elementos relacionados à educação. Conforme Paraíso (2004),

Usando uma linguagem que recebe influências da chamada "filosofia da diferença", do pós-estruturalismo, do pós-modernismo, da teoria queer, dos estudos feministas e de gênero, dos estudos multiculturalistas, póscolonialistas, étnicos, ecológicos, etc., as teorias pós-críticas realizam, no campo educacional brasileiro, substituições, rupturas e mudanças de ênfases em relação às pesquisas críticas. Suas produções e invenções têm pensado práticas educacionais, currículos e pedagogias que apontam para a abertura, a transgressão, a subversão, a multiplicação de sentidos e para a diferença (PARAÍSO, 2004, p. 284-285). 
O número expressivo de trabalhos no indicador "Sem definição pelo autor" justifica-se pela falta de definição explícita dos pesquisadores em relação à perspectiva teórica que embasam seus estudos; destaca-se que em alguns deles há autores referências cujas perspectivas teóricas são de natureza epistemológica diferenciada. A Tabela 3 indica o número de trabalhos apresentados conforme abordagem teórica/ano, a partir das definições dos autores dos trabalhos.

Tabela 3 - Abordagens teóricas, a partir da definição dos autores, dos trabalhos publicados nas Reuniões Científicas Anuais da ANPEd, por ano/Reunião Científica Anual

\begin{tabular}{|c|c|c|c|c|c|c|c|}
\hline Abordagens teóricas & $\begin{array}{c}{33^{\mathbf{a}}} \\
\text { ANPEd } \\
2010\end{array}$ & $\begin{array}{c}34^{\mathrm{a}} \\
\text { ANPEd } \\
2011\end{array}$ & $\begin{array}{c}3^{\mathbf{a}} \\
\text { ANPEd } \\
2012\end{array}$ & $\begin{array}{c}36^{\mathbf{a}} \\
\text { ANPEd } \\
2013\end{array}$ & $\begin{array}{c}37^{\mathbf{a}} \\
\text { ANPEd } \\
\mathbf{2 0 1 5}\end{array}$ & $\begin{array}{c}\mathbf{3 8}^{\mathbf{a}} \\
\text { ANPEd } \\
2017\end{array}$ & $\begin{array}{c}\text { TOTAL } \\
\text { (Últimas } \\
\text { seis } \\
\text { Reuniões } \\
\text { Científicas } \\
\text { Anuais) }\end{array}$ \\
\hline Estudos sobre currículo & 0 & 0 & 0 & 0 & 1 & 0 & 1 \\
\hline Pensamento Freireano & 0 & 0 & 0 & 0 & 0 & 1 & 1 \\
\hline Hermenêutica Filosófica & 0 & 0 & 0 & 1 & 0 & 0 & 1 \\
\hline Histórico-Crítica & 1 & 0 & 0 & 0 & 0 & 1 & 2 \\
\hline Teoria Crítica & 0 & 1 & 0 & 0 & 1 & 0 & 2 \\
\hline Psicanálise e Filosofia & 1 & 0 & 0 & 1 & 0 & 0 & 2 \\
\hline $\begin{array}{l}\text { Estudos sobre Linguagem e } \\
\text { Discurso }\end{array}$ & 1 & 0 & 0 & 0 & 1 & 0 & 2 \\
\hline Pensamento Sistêmico & 0 & 0 & 1 & 2 & 0 & 1 & 4 \\
\hline $\begin{array}{l}\text { Abordagem "Ciclo } \\
\text { Políticas" }\end{array}$ & 0 & 0 & 1 & 2 & 1 & 0 & 4 \\
\hline Estudos Culturais & 1 & 1 & 1 & 0 & 1 & 0 & 4 \\
\hline Estudos Surdos & 3 & 3 & 4 & 0 & 1 & 0 & 11 \\
\hline Histórico-Cultural & 3 & 4 & 2 & 1 & 6 & 2 & 18 \\
\hline $\begin{array}{l}\text { Materialismo } \quad \text { Histórico- } \\
\text { Dialético }\end{array}$ & 3 & 2 & 3 & 4 & 4 & 3 & 19 \\
\hline Pós-Estruturalismo & 3 & 4 & 5 & 2 & 6 & 6 & 26 \\
\hline $\begin{array}{l}\text { Sem definição explícita pelo } \\
\text { autor }\end{array}$ & 6 & 12 & 8 & 9 & 9 & 4 & 48 \\
\hline
\end{tabular}

Fonte: elaborada pelas autoras.

\section{Considerações finais}

O estudo sobre os trabalhos apresentados no decorrer das Reuniões Científicas Anuais da ANPEd, no GT 15 - Educação Especial, dos anos já mencionados, apresentou um conjunto de produções com diferenciados objetos de investigação, dentre os mais estudados aqueles voltados às políticas públicas relacionadas à Educação Especial (15\%), à surdez, em diversos contextos e delimitação de análise (14\%), às práticas pedagógicas diante dos processos inclusivos (13\%) e ao Atendimento Educacional Especializado como prática na escola regular inclusiva (12\%). Os temas de pesquisa mais recorrentes nessas últimas reuniões parecem estar 
relacionados à proposição da Política Nacional (BRASIL, 2008), que pode ser a mais provável razão do interesse investigativo entre os pesquisadores da área.

A construção deste estado do conhecimento, tendo em vista as pesquisas recentes na área da Educação Especial, veiculadas pela ANPEd, revelou a predominância da Região Sul (37\%), do estado do Rio Grande do Sul e das instituições públicas de ensino superior (85\%) como os espaços com maior participação/produção do conhecimento científico na área da Educação Especial, no decorrer dos últimos seis anos, nas Reuniões Científicas Anuais da ANPEd. As Regiões Sudeste (33\%) e Nordeste (16\%) são também regiões com número significativo de produções veiculadas nas últimas Reuniões Científicas.

Entretanto, como contraponto, percebe-se a baixa publicização das Regiões CentroOeste $(11 \%)$ e Norte (3\%) do país. Há a publicação de apenas dezesseis trabalhos advindos da Região Centro-Oeste e apenas cinco trabalhos provenientes da Região Norte nessas últimas Reuniões Científicas, o que nos faz questionar: não há inscrições de trabalhos advindas dessas regiões do país para a participação nas Reuniões Científicas? Os pesquisadores das Regiões Centro-Oeste e Norte do país que enviam seus trabalhos para a publicação de suas pesquisas nas Reuniões Científicas não obtêm êxito na seleção de seus textos? Ou esses pesquisadores estão optando por divulgar os resultados de suas pesquisas em outros eventos/periódicos científicos? Dentre as hipóteses, o baixo número de programas de pós-graduação em educação situados na Região Norte e o fato de apenas um dos programas conter uma linha de pesquisa voltada aos estudos da Educação Especial, apesar de outras linhas de pesquisa também produzirem pesquisas na área, podem ser indicativos de participação da Região Norte, o que não há é um número expressivo de trabalhos na área de Educação Especial.

No que se refere às abordagens metodológicas das pesquisas, a maioria dos autores que explicitaram suas escolhas metodológicas definiram suas investigações como pesquisas de natureza qualitativa (36\%). A partir da definição explícita dos autores nos resumos/textos, numa análise simples, poderíamos afirmar que as entrevistas se configuram como a técnica mais utilizada dentre as pesquisas, em um total de $32 \%$. Contudo, a análise de documentos, se somada em suas variantes (análise de teses e dissertações, análise de documentos midiáticos, análise de documentos escolares e análise de documentos oficiais) é utilizada em maior número de trabalhos do que as entrevistas, sendo citada num total de 54 trabalhos, totalizando $37 \%$ das produções. Aliado a esse dado, destacamos que a pesquisa documental foi o tipo de pesquisa mais afirmado pelos autores que explicitaram as escolhas metodológicas de suas pesquisas nos resumos/textos publicados, totalizando $20 \%$ das produções. 
Evidencia-se que os trabalhos publicados/apresentados nesses últimos anos nas Reuniões Científicas da ANPEd estão fundamentados em diferenciadas abordagens teóricas de estudo, o que demonstra a multidisciplinaridade de olhares, a partir de diferentes perspectivas, para os objetos de estudos no campo da Educação Especial. Destaca-se que uma quantidade significativa de trabalhos não continha de forma explícita as escolhas teóricas de seus autores; e que, em alguns deles, era percebida a referência de autores aliados a perspectivas teóricas distanciadas entre si. Entretanto, a abordagem epistemológica mais citada entre os trabalhos refere-se aos estudos pós-estruturalistas (em 26 trabalhos é explicitada, ou 18\%), e pode ser justificada pela influência desses estudos nas pesquisas em educação no país, que tiveram sua ascensão a partir da década de 90 (PARAÍSO, 2004; RIBEIRO, 2016).

A pesquisa sobre a pesquisa favorece o conhecimento do pesquisador diante do campo de estudos em que está inserido. Dá-lhe as condições de perceber os temas de estudo mais estudados, as perspectivas teóricas mais aprofundadas e as metodologias investigativas mais utilizadas nas pesquisas recentes. Além disso, alerta acerca dos temas e objetos de estudo que precisam ser mais investigados, tendo em vista as lacunas do campo científico em que se quer fazer pesquisa. Os temas/objetos de estudo que menos aparecem nos trabalhos apresentados nas reuniões estão relacionados à problemáticas não menos importantes para a área, dentre elas pesquisas relacionadas aos sujeitos com transtornos/dificuldades de aprendizagem que deixam de ser público-alvo da Educação Especial a partir da Política Nacional (2008), e que, conforme mostram algumas pesquisas, acabam sendo atendidos, no Atendimento Educacional Especializado, por professores de Educação Especial nas escolas regulares (THESING; COSTAS, 2016; FERRAZ; MEDEIROS; COSTAS, 2017), e que chegam à educação superior (FREITAS, 2019) sendo atendidos pelos profissionais do AEE dos núcleos de acessibilidade. Nota-se também a falta de produções que estudam a deficiência física e as diferentes síndromes, e a inclusão desses sujeitos nas instituições regulares, e temáticas emergentes, como a intersecção gênero e deficiência.

Esse estudo, com o intuito de trazer contribuições para vislumbrar as produções no campo da Educação Especial, é uma das possibilidades de construção do estado de conhecimento, tendo em vista o número expressivo de pesquisas e bancos de dados relevantes, nos âmbitos nacional e internacional, a serem explorados em estudos futuros. Olhar para os processos investigativos voltadas às temáticas da Educação Especial, para compreender seus processos e analisar o que vem sendo produzido na área, é "uma tarefa coletiva e de longo prazo, que precisa envolver todos aqueles que de alguma forma se 
preocupam com o desenvolvimento e com os resultados das pesquisas na área da educação" (ANDRÉ, 2001, p. 52). Neste contexto, Fantinato e Mendes (2016) alertam que, apesar do número de pesquisas na área da educação especial ser significativo e crescente, "parece que o conhecimento produzido pelas pesquisas não têm gerado impacto na construção e na prática das políticas educacionais desta área" (FANTINATO; MENDES, 2016, p. 2089). Tal constatação merece atenção e preocupação diante dos objetivos da pesquisa e seus desdobramentos nos cenários educacional e político no país.

Isso porque as pesquisas no campo de Educação Especial, seus objetos e perspectivas de análise, não são elementos isolados, à parte da sociedade e das produções históricas e materiais como um todo. As suas produções são elementos inter-relacionados a uma estrutura macro, marcada por mudanças, tensões e contradições políticas e epistemológicas. A pesquisa em educação é, como o fazer pedagógico, um ato político (FREIRE, 1991) e que, comprometida com determinadas concepções de homem, de educação e de sociedade, pode ser um instrumento de luta e resistência à alienação e à exploração do trabalho docente, a favor de uma "educação para além do capital" (MÉSZAROS, 2008).

\section{REFERÊNCIAS}

BRASIL. Política nacional de educação especial na perspectiva inclusiva. Brasília, DF: SEESP, 2008.

ANDRÉ, Marli. Pesquisa em educação: buscando rigor e qualidade. Cadernos de Pesquisa, n. 113, p. 51-64, 2001.

FANTINATO, Aline Costa; MENDES, Enicéia Gonçalves. Análise da produção científica em dissertações e teses com foco no funcionamento das salas de recursos. Revista IberoAmericana de Estudos em Educação, v. 11, n.4, p. 2087-2103, out./dez. 2016.

FELICIO, Natália Costa de; PEREZ CAMPOS, Juliane Ap. de Paula. A inclusão escolar no contexto do ensino médio: análise das produções em periódico científico. Revista IberoAmericana de Estudos em Educação, v. 12, n. 3, p. 1710-1720. jul./set. 2017.

FERRAZ, Ana Paula dos Santos; MEDEIROS, Bruna de Assunção; COSTAS, Fabiane Adela Tonetto. Escolarização dos estudantes com dificuldades de aprendizagem frente às atuais políticas de inclusão. In: SOARES, Ilma Maria Fernandes; ALMEIDA, Márcia Tereza Fonseca; SILVA, Renato Martins e (Orgs.). Temas em Debate. 1. ed. Rio de Janeiro/RJ: Dictio Brasil, 2017, v. II, p. 45-73.

FERREIRA, Júlio Romero; BUENO, José Gerado Silveira. Os 20 anos do GT Educação Especial: gênese, trajetória e consolidação. Revista Brasileira de Educação Especial, v. 17, p. 143-170, maio/ago. 2011. 
FREIRE, Paulo. A educação é um ato político. Cadernos de Ciência, Brasília, n. 24, p. 2122, 1991.

FREITAS, Clariane do Nascimento de. Dislexia, educação superior e aprendizagem: uma análise da subjetividade e dos processos compensatórios a partir da Teoria Histórico-Cultural. Orientadora: Fabiane Adela Tonetto Costas. 2019. 223 f. Tese (Doutorado em Educação) Universidade Federal de Santa Maria, Centro de Educação, Programa de Pós-Graduação em Educação, RS, 2019.

GARCIA, Rosalba Maria Cardoso; MICHELS, Maria Helena. A política de educação especial no Brasil (1991-2011): uma análise da produção do GT15 - educação especial da ANPED.

Revista Brasileira de Educação Especial, v. 17, p. 105-123, maio/ago. 2011.

JESUS, Denise Meyrelles de; BARRETO, Maria Aparecida Santos Corrêa; GONÇALVES, Agda Felipe da Silva. A formação do professor olhada no/pelo GT-15 - educação especial da ANPEd: desvelando pistas. Revista Brasileira de Educação Especial, v. 17, p. 77-92, maio/ago. 2011.

MARCONI, Marina de Andrade; LAKATOS, Eva Maria. Fundamentos de metodologia científica. 6. ed. 7. reimpr. São Paulo: Atlas, 2009.

MARQUES, Luciana Pacheco; CARNEIRO, Carla Toscano; ANDRADE, Josiane da Silva; MARTINS, Nathalia Toledo; GONÇALVES, Rafael Marques. Analisando as pesquisas em educação especial no Brasil. Revista Brasileira de Educação Especial, v. 14, n. 22, p. 251272, maio/ago. 2008.

MÉSZAROS, István. A educação para além do capital. 2. ed. São Paulo: Boitempo, 2008.

MOROSINI, Marília Costa. Estado do conhecimento e questões do campo científico.

Educação, Santa Maria, v. 40, n. 1, p. 101-116, 2015.

MOROSINI, Marília Costa; FERNANDES, Cleoni Maria Barboza. Estado do Conhecimento: conceitos, finalidades e interlocuções. Educação Por Escrito, v. 5, n. 2, p. 154-164, 2014.

PARAÍSO, Marlucy Alves. Pesquisas pós-críticas em educação: esboço de um mapa.

Cadernos de Pesquisa, v. 34, n. 122, p. 283-303, maio/ago. 2004.

RIBEIRO, Márden de Pádua. Teorias críticas e pós-críticas: pelo encontro em detrimento do radicalismo. Movimento - Revista de Educação, ano 3, n. 5, p. 284-317, 2016.

ROMANOWSKI, J. P.; ENS, R. T. As pesquisas denominas do tipo "Estado da Arte" em educação. Diálogo Educacional, v. 6, n. 19, p. 37-50, 2006.

SÁNCHEZ GAMBOA, Sílvio. Pesquisa em educação: métodos e epistemologias. 2. ed. Chapecó: Editora Argos, 2007. 193 p.

SENADO FEDERAL. Gabinete do Senador Major Olimpio. Projeto de Lei n., de 2019. Institui a Política Nacional para Educação Especial e Inclusiva, para atendimento às pessoas com Transtorno Mental, Transtorno do Espectro Autista (TEA), deficiência Intelectual e Deficiências Múltiplas. Brasília, 2019. Disponível em: https://legis.senado.leg.br/sdleg- 
getter/documento?dm=7972697\&ts=1571777110791\&disposition=inline. Acesso em: fev. 2020.

THESING, Mariana Luzia Corrêa; COSTAS, Fabiane Adela Tonetto. As qualidades de um professor de Educação Especial: um professor multifuncional? In: VII Congresso Brasileiro de Educação Especial e X Encontro Nacional dos Pesquisadores da Educação Especial, 2016, São Carlos, SP. Anais eletrônicos[...] São Carlos: UFSCar, 2016. Disponível em: https://proceedings.galoa.com.br/cbee7/trabalhos/as-qualidades-de-um-professor-deeducacao-especial-um-professor-multifuncional. Acesso em: 15 ago. 2017.

\section{Como referenciar este artigo}

THESING, Mariana Luzia Corrêa; COSTAS, Fabiane Adela Tonetto. As pesquisas em Educação Especial na ANPEd: a produção do conhecimento nas reuniões científicas nacionais. Revista IberoAmericana de Estudos em Educação, Araraquara, v. 15, n. 3, p. 1146-1166, jul./set. 2020. eISSN: 1982-5587. DOI: https://doi.org/10.21723/riaee.v15i3.12426

Submetido em: 05/04/2019

Revisões requeridas em: 20/07/2019

Aprovado em: 25/11/2019

Publicado em: 20/02/2020 